\title{
Modified pre-surgical technique for optimizing the mandibular deviation using gunning's splint as discontinuity mandibulectomy prosthesis: A Case Report
}

\author{
Dubey $\mathbf{P K}^{1}$, Sethuraman $\mathbf{R}^{2}$ \\ ${ }^{1}$ Dr Pavan Kumar Dubey, Consultant Prosthodontist,The Dental Evolution, Varanasi, Uttar Pradesh, ${ }^{2}$ Dr Rajesh \\ Sethuraman, Professor, Department of Prosthodontics, K.M. Shah Dental College, Vadodara, Gujarat, India.
}

Address for correspondence: ${ }^{1}$ Dr Pavan Kumar Dubey, Email: drpavan26@gmail.com

\begin{abstract}
Patients who have undergone mandibular resection are generally co-operative and philosophical in respect to their conditions. The prosthodontic prognosis is dependent on a number of complex factors. The extent of bony and soft tissue resection has significant impact. Patients with lateral discontinuity defects of the mandible have little hope of achieving pre-surgical levels of masticatory efficiency, however certain measures can be sought off to minimize the post surgical deviation. In this case report an effort has been made by incorporating the gunning's splint with modified mechanism of interlocking in the form of mandibular discontinuity prosthesis with an intent to minimize the post surgical deviation
\end{abstract}

Keywords: Edentulous, Resection prosthesis, Stabilization

\section{Introduction}

In lateral discontinuity mandibulectomy defects the arc of closure is angular rather than vertical, there is unilateral condensation of forces exclusively on the unresected side. Also, because of rotation of the mandible in the frontal plane, the resected side drops down out of occlusion and hence location of fulcrum line is also not easy. Use of mesial, occlusal rest on the distal abutment tooth, placing the retainers at the height of contour, or by using retainers with with adequate flexibility, will prevent excessive forces being transferred on the abutment teeth[1].

\section{Terminologies}

Marginal mandibulectomy- implies that a margin of bone is resected but the continuity of the mandible is maintained [2].

Discontinuity mandibulectomy- a discontinuity resection of the mandible indicates that a portion of the mandible is resected, and the condyle to condyle continuity of the mandible is disrupted [2].

\footnotetext{
Manuscript received: $17^{\text {th }}$ Aug 2015

Reviewed: $27^{\text {th }}$ Aug 2015

Author Corrected: $7^{\text {th }}$ sept 2015

Accepted for Publication: $16^{\text {th }}$ Sept 2015
}

Gunning's splint -a device fabricated from casts of edentulous maxillary and mandibular arches to aid in reduction and fixation of a fracture [3].

It is so named on the name of English born American dentist Thomas Brian Gunning, 1813-1889 after his work on the fabrication of above mentioned prosthesis. His initial work described 4 types of splints used in the treatment of jaw fractures (1866-67), which allowed openings for saliva flow, nourishment and speech [3].

It holds together fractured segments of bones and immobilizes the jaws. In an edentulous patient no hard tissues will be available for stabilization and retention of splints. The retention is mainly obtained by wiring to underlying bony tissues. A gunning splint can be a one piece or a two piece gunning splint. A two piece gunning splint is used on an edentulous jaw to maintain centric or vertical relationship for immobilization and inter maxillary fixation [4].

Evaluating factors for constructing prosthesis for mandibulectomy patients: Norman G Schaff [5] has described following factors for evaluating mandibulectomy patients before constructing prosthesis. 
i) Pre-operative success with complete denturs

ii) Over-all vigor of the patient.

iii) Patient awareness of present oral status and limitations

iv) Amount of residual mandible

v) Amount of deviation

vi) Remaining kinesthetic sense and control

vii) Actual present ridge relationship

viii) Nature of denture bearing area

ix) Type of treatment patient has received

x) Status of the patient's disease.

\section{Case Rreport}

A 56 year old edentulous female patient was referred from department of oral surgery, K.M. Shah dental college, Vadodara. She had to undergo for hemimandibulectomy. Since all the teeth in the maxillary and mandibular arches were periodontaly compromised and were indicated for extraction. Therefore it was decided to fabricate a splint before the surgery and utilize the splints to immobilize mandible at the time of surgery itself to optimize the mandibular deviation after surgery.

\section{The Technique}

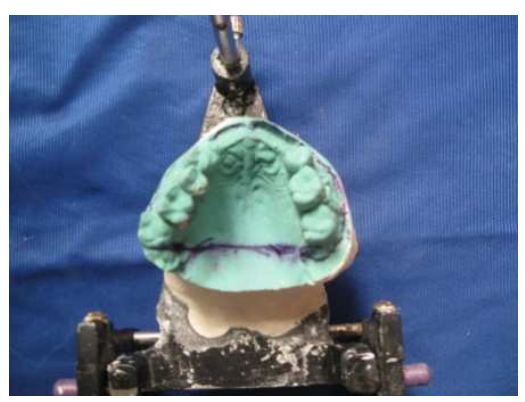

Fig. 1

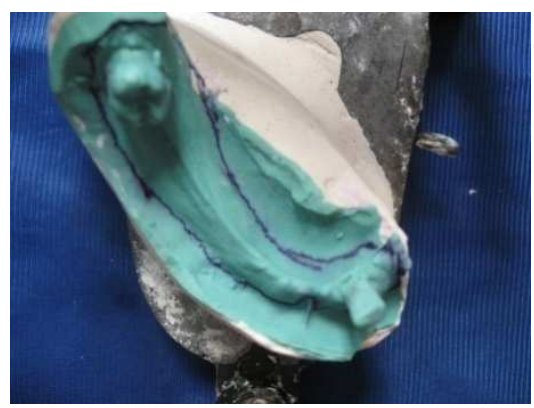

Fig.2
Steps 1 - After examination, preliminary impression of maxillary and mandibular arch was made with alginate impression material and Jaw Relation Procedure was Performed .

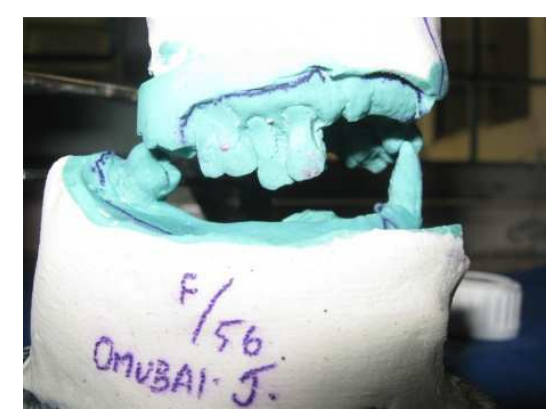

Fig. 3 
Step 2 - The teeth were removed from the mounted cast

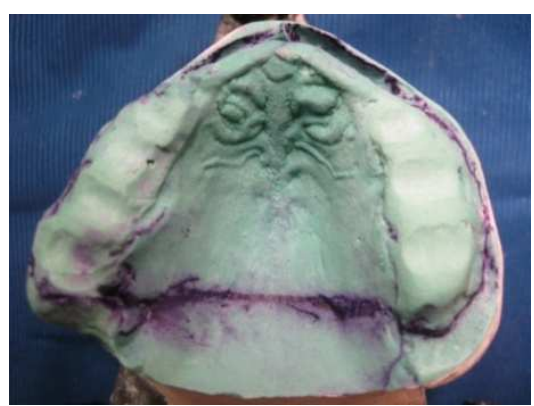

Fig. 4 (A)

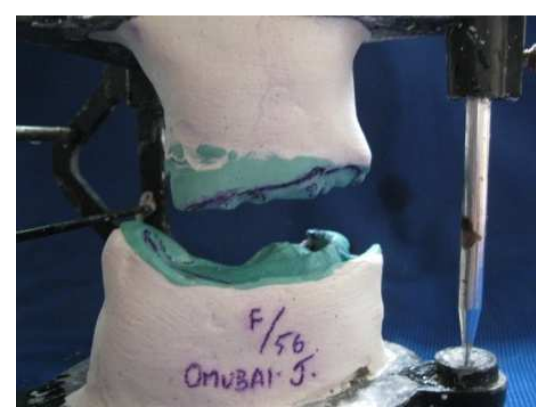

Fig 4 (B)

Step 3- Wire hooks were embedded in the buccal flange and used for inter maxillary fixation

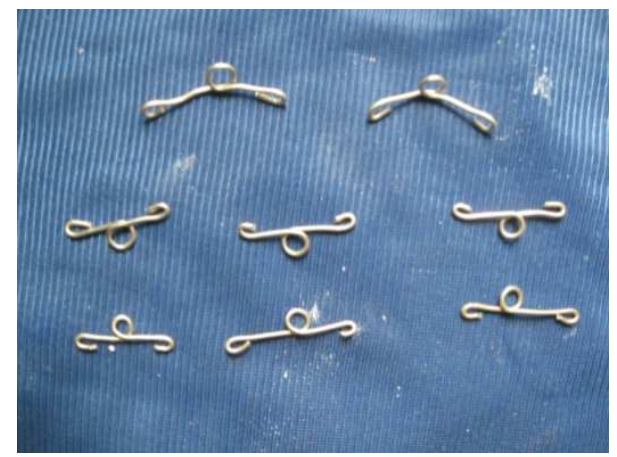

Fig. 5

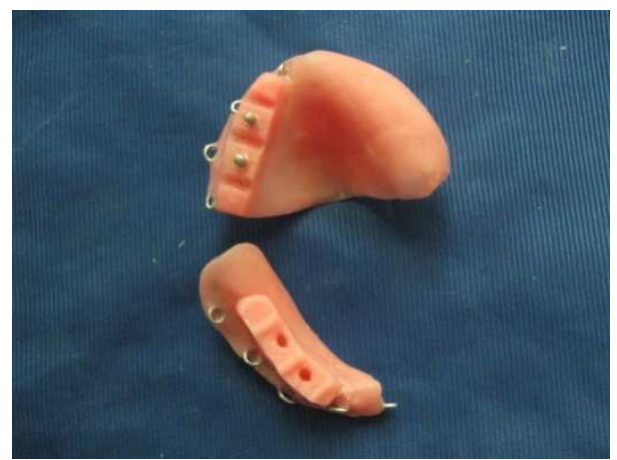

Fig .6

Step- 4 - A locking mechanism was introduced. Male projections (tungsten carbide burs) about 3 mm are made on occlusal surface of one acrylic rim for anchorage by self-cure to grooves (Females) on the other acrylic rim during fixation.

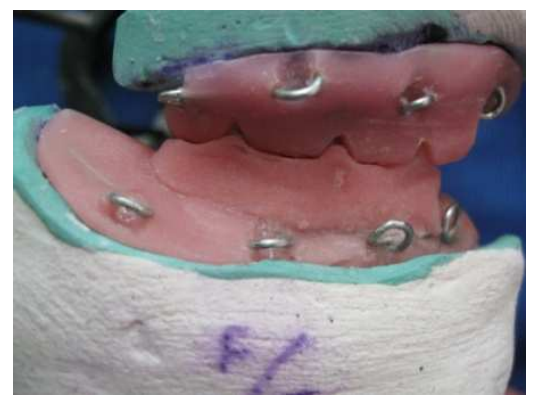

Fig. 7

\section{Discussion}

The sole purpose for modification in the fabrication of gunning's splint pre-operatively is to ensure the correct maxillo-mandibular relation [6] at which the prosthesis would be placed post-operatively. It is well documented that the muscle pull of unaffected site is so strong that it requires Intermaxillary fixation which might not be possible post operatively. Similarly, Fracture of edentulous maxillary and mandibular arches in an elderly patient pose serious challenge for achieving the stabilization. Surgical intervention using miniplate osteosyntesis may not be practical approach. Therefore, interdisciplinary approach including a prosthodontist and a surgeon is required where gunning splints may overcome the problem.

\section{Conclusion}


The prosthetic prognosis of removable prosthesis for patients with resections of the tongue and the mandible is quite variable. Following resection of the mandible, besides the progression of healing, the primary determinant for fabrication of a definitive prosthesis is related to occlusion. Before beginning with the fabrication of a definitive prosthesis the prosthodontist must ensure that all conventional restorative procedures are complete and an acceptable occlusion is achieved.

\section{Funding: Nil, Conflict of interest: Nil, Permission from IRB: Yes}

\section{References}

1. Frank J. Kratochvil. Influence of occlusal rest position and clasp design on movement of abutment teeth. J Prosthet Dent. 1961; 13:114-121
2. Zarb, Hobrick, Eckert, Jacob, Fenton, Finer, Chang, Koka. Prothodontic treatment for edentulous patients. Elsevier; 13th edition: 377.

3. The glossary of prosthodontic terms. J Prosthet dent. 2005 july ; 94(1): 42.

4. Fraser-Moodie W. Mr. Gunning and his splint. Br J Oral Surg. 1969 Nov; 7(2):112-5.

5. Norman G Schaff .Oral reconstruction for edentulous patients after partial mandibulectomies. J Prosthet Dent. 1976 ; 36( 3): 292-297.

6. Sheldon Winkler : Essentials of complete denture prosthodontics.AITBS Publishers: 2nd Edition:83.

\section{How to cite this article?}

Dubey PK, Sethuraman R. Modified pre-surgical technique for optimizing the mandibular deviation using gunning's splint as discontinuity mandibulectomy prosthesis: A Case Report. Int J Med Res Rev 2015;3(8):902-905. doi: 10.17511/ijmrr.2015.i8.154. 